These cases illustrate nearly all the essential symptoms and signs of the disease. Both cases occurred in Hebrews. The great majority of cases are among this race. Sachs and others maintain there are no proved cases without Jewish ancestry. Haveroch, ${ }^{14}$ however, reports 7 out of 86 cases among other nationalities. In one of my cases another child in the same family had died from the disease. It frequently occurs in several members of the same family. Both children appeared normal at birth and developed normally up to a certain point and then began to show signs of weakness. This weakness grew progressively worse, involving the muscles of the neck, trunk and extremities. The paralysis was usually spastic in type, but at times seemed flaccid. This alternation in the type of paralysis is characteristic of the disease.

Both cases showed some disturbance of vision - this has gone on to total blindness in the second case. Almost constant nystagmus was present, and in addition a rolling upward of the eyes into the head. The fundi showed the typical condition of this disease - a dark mahogany-red spot on a white background, seen in the macula region.

The first child made a peculiar gurgling sound with respiration and the second child you have heard make the same noise here to-night. Drooling was present in one case. The second case showed some disturbance in hearing, perhaps associated with an old otitis media, but deafness has been mentioned as occurring in this disease due to the changes in the nerves of the central nervous system. Both children showed an excitable or irritable nervous system, evidenced by the jumping of the child at slight noises and by the tendency to cry at small provocation.

In brief, the symptoms may be summarized as follows:

(1) A progressive paralysis - flaccid or spastic in type - occurring in an infant previously normal and well developed.

(2) Blindness with typical changes in the fundi of the eyes.

(3) Mental deficiency going on to idiocy.

(4) Nystagmus, drooling, gurgling in the throat.

(5) Occurrence in Hebrews, often in several members of the same family.

The pathological findings of this disease are distinctive. The lesions are confined to the central nervous system. Every cell of the entire central gray matter, brain, cord and spinal ganglia, is involved. The changes are degenerative in type and consist of a swelling of the cell protoplasm which by pressure causes a mechanical destruction of the cell fibrils. Ultimately the cell body is a mass of detritus. The axis cylinders are not involved in the process. The characteristic appearance in the fundi of the eyes is due to the degeneration of the ganglion cells of the retina and the nerve fibers of the optic nerves, which are, of course, really a part of the central nervous system. The cells are more numerous in the macula region than elsewhere, so that region appears white. The red spot is due to the contrast of the retinal vessels with the white surroundings.
The changes in the nerve cells are probably produced by some defect inherent in the nerve cells, which defect is transmitted through the Hebrew inheritance. This condition is not congenital because if so there is no reason why the disease should invariably progress to a fatal termination. These infants possess an abnormally exhaustible nerve cell protoplasm which being paralyzed by the strain of earliest function soon degenerates.

Vogt ${ }^{15}$ and others have described a juvenile form of this disease. It occurs later in life from the eighth to the twelfth year - and leads to a fatal termination after a few years. There is progressive paralysis and idiocy associated with blindness, but the eyes do not show the changes in the macula seen in the infantile form. It is not confined to Hebrews. At autopsy the histological findings bear a close similarity to those already described.

The prognosis of this disease is, of course, hopeless. No cases of the infantile type have lived to be over three years of age and the majority die before reaching the age of two years. No known treatment influences in any way the progress of the disease.

REFERENCES.

1 Waren-Tay: Trans. Ophthal. Soc. United Kingdom, 1881, i, 55.

Waren-Tay: Ibid., 1884, iv, 158 .

Knapp: Trans. Heidelberg Ophthal. Soc., 1885, xvii, 217.

Sachs: Jour. Nerv. and Ment. Dis., 1887, xiv, 541.

Kingdom: Trans. Ophthal. Soc. United Kingdom, 1892, xii, 126.

-Wadsworth: Trans. Am. Ophthal. Soc., 1887, iv, 572.

7 Sachs: Jour. Nerv. and Ment. D is., 1892, xix, 603.

8 Waren-Tay: Trans. Ophthal. Soc. Ünited Kingdom, 1892, xii, 125. Sachs: New York Med. Jour., 1896, 1xiii, 697.

10 Abt: Am. Jour. Dis. Child., 1911, i, 59.

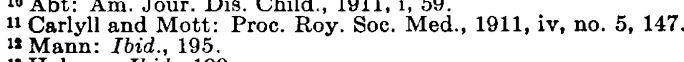

18 Holmes: Ibid., 199

14 Haversoch: Cap. ces lek., 1904. Reviewed in Neurol. Centralbl., 1904, xxiii, 948 .

15 Vogt: Arch. für Kinderh., 1909, li, 1.

\section{A CARD FOR THE RAPID CALCULATION OF MILK MODIFICATIONS.}

\author{
BY JAMES HERBERT YOUNG, M.D., NEWTON, MASG.
}

The calculation necessary before we can instruct the mother or nurse how to prepare a given milk modification is, for most of us, a more or less lengthy process, while for some it is not only a lengthy, but a difficult mathematical problem. The aim in the production of this card has been to overcome these difficulties, namely, to save time and to reduce mathematics to a minimum, and at the same time to devise a simple method of broad scope, not only in milk and cream modifications, but in whey mixtures as well. There is nothing new about the method of calculating or preparing milk modifications; only the manner in which it is presented is original.

A celluloid envelope, 5 inches long and 3 inches wide, open at the top, contains two celluloid cards. Upon both sides of these cards are printed the figures necessary for the preparation of 20 , 32,40 and 48 ounce mixtures. The front of the envelope is divided into four sections, headed "fat," "proteid," "sugar" and "whey," with subheadings of "percentage desired" and " number of ounces" of the various ingredients. Above 
these subheadings are perforations through which figures on the card are read. To which mixture these figures belong is shown through perforations in the upper right or left hand corner of the envelope. By pushing the cards up or down until the desired percentage shows in the proper column, the number of ounces of cream or milk needed may be found in the next column.

For example, suppose we wish to prepare a 3.60-7.0-1.40 mixture for an infant taking six feedings of 6 ounces each. The 40-ounce mixture card is placed so that 40 -ounce mixture shows through the proper perforation. We first determine how many ounces of cream are needed to give $3.60 \%$ fat. Pull the card out until 3.60 appears in the "percentage desired " column under the heading "fat" and in the next column. we find that 9 ounces of $16 \%$ cream are required. In the same way with the proteid, when 1.40 appears above the subheading "percentage desired," under the heading "proteid" we find in the next column that $17 \frac{1}{2}$ ounces of milk and cream are needed to give the required percentage. We already have 9 ounces of cream, so we must add $8 \frac{1}{2}$ ounces of skimmed milk. Without further manip- calculated as containing no fat. The sugar in the milk and cream is calculated as $4.50 \%$, the proteid in the milk and cream as $3.20 \%$. Whey is calculated as containing no fat, $5.0 \%$ sugar and $1 \%$ proteid.

A casual glance at the card will show the absence of the conventional increase of the fat and proteid in multiples of $.25 \%$. Each increase in these elements as given by the card is as follows:

$\begin{array}{lcc} & \begin{array}{c}\text { Fat. } \\ \text { Per cent. }\end{array} & \begin{array}{c}\text { Proteid. } \\ \text { Per cent. }\end{array} \\ \text { 20 ounce mixture, } & .20 & .16 \\ 32 \text { ounce mixture, } & .25 & .20 \\ 40 \text { ounce mixture, } & .20 & .20 \\ 48 \text { ounce mixture, } & .50 & .33\end{array}$

The reason for this is that an attempt has been made to avoid fractions of ounces as far as possible and, except in the 20 -ounce mixture, $\frac{1}{2}$ ounce is the smallest unit used. In other words, instead of taking a given percentage and finding out how many ounces of milk or cream are needed, the even ounce or half ounce is taken and the resulting percentage given. If one wishes to make a modipercentage given. If one wishes to make a modi-
fication not given, for example, a $2.25 \%$ proteid

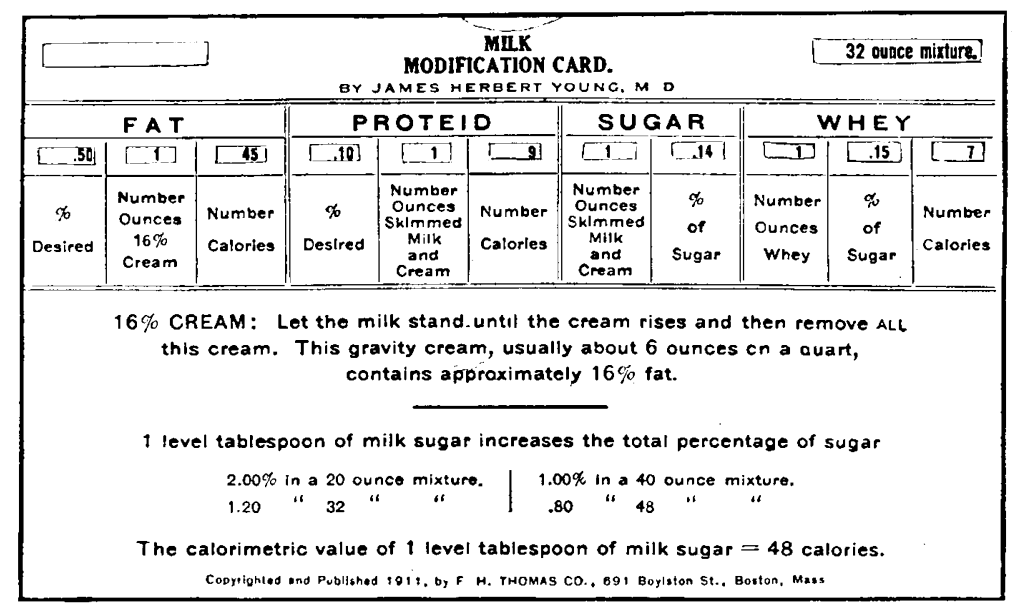

ulation of the card we find under the heading in a 40-ounce mixture, it can be readily calculated "sugar" that $17 \frac{1}{2}$ ounces of milk and cream add from the top line of each card, which shows the to our mixture $1.96 \%$ of sugar. By referring to amount of increase in fat, sugar and proteid one the table on the front of the card we find that one ounce of cream or skimmed milk will give in the level tablespoon of milk sugar in a 40-ounce total mixture. In this case $2.20 \%$ is the nearest mixture increases the sugar $1 \%$, and as we need to the desired percentage given. The first line about $5.0 \%$ to make the desired $7 \%, 5$ level on the card shows that one ounce of skimmed tablespoons of milk sugar will be necessary. milk or cream adds $.08 \%$ proteid. As we presum-

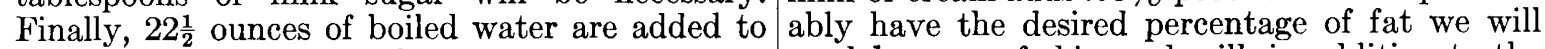
make the total amount of 40 ounces.

For the sake of simplicity both in the making of the card and in the preparation of the modification, only a $16 \%$ or gravity cream is used. This, of course, imposes limitations, but these limitations are quickly evident. For example, to obtain a $1.60 \%$ fat in a 20 -ounce mixture, 2 ounces of cream are needed. Under the heading " proteid" we find that 2 ounces of milk and cream, one or both, give $.32 \%$ proteid. This, then, is the lowest percentage of proteid we can get in a 20 -ounce mixture with $1.60 \%$ fat. Skimmed milk is need $\frac{1}{2}$ ounce of skimmed milk in addition to the amount necessary to give $2.20 \%$, making $2.24 \%$, as near as we can come without deceiving ourselves by measuring in drams.

The calculation of whey mixtures can be accomplished as easily and as quickly by the card as the calculation of simple mixtures. In making whey mixtures two suppositions are taken, which, although not scientifically accurate, are accurate enough for all practical purposes. These are (1) that the proteid in the milk and cream shall be calculated as all casein and (2) that 
When all the diluent is whey, the whey proteid is approximately $.90 \%$.

When $\frac{3}{4}$ the diluent is whey, the whey proteid is approximately $.75 \%$.

When $\frac{1}{2}$ the diluent is whey, the whey proteid is approximately $.50 \%$.

When $\frac{1}{4}$ the diluent is whey, the whey proteid is approximately $.25 \%$.

Suppose we wish to make a 32-ounce mixture containing $2 \%$ fat, $6.50 \%$ sugar, $.50 \%$ whey proteid and $.40 \%$ casein. Proceeding as before, we find that 4 ounces of $16 \%$ cream are needed. To obtain a $.40 \%$ proteid, 4 ounces of skimmed milk and cream are necessary. We already have 4 ounces of cream, so no skimmed milk is needed. As 4 ounces of cream provide the necessary fat and casein, the amount of diluent will be 28 ounces, and as we want $.50 \%$ whey proteid, one half the diluent must be whey. The next step is to find the percentage of sugar we already have in the mixture. Under the heading "sugar" we find that 4 ounces of cream adds $.56 \%$ sugar, and under the heading "whey" that 14 ounces of whey increases the sugar $2.18 \%$, a total of $2.74 \%$. As one level tablespoon of milk sugar in a 32-ounce mixture increases the total percentage of sugar $1.20 \%$, 3 level tablespoons will give, approximately, the amount desired.

A column headed "number of calories" has been added under the main headings "fat," "proteid" and "whey," not, however, to provide a method of feeding on a caloric basis, but as a means of quickly determining the caloric value of a formula. In writing directions for making a home modification, as we write the number of ounces of the various ingredients, we also write down the number of calories as found in the next column to the right. To return to our first example of a 40-ounce mixture containing $3.60 \%$ fat, $7 \%$ sugar, $1.40 \%$ proteid.

9 ounces of cream,

$17 \frac{1}{2}$ ounces of cream and skimmed milk,

Calories.

5 level tablespoons of milk sugar ( 48 calories in

1 level tablespoon),

Total,

This is the caloric value of 40 ounces; the infant was to take but 36 ounces, or 9 the whole amount; ${ }_{10}^{9}$ of $808=727$ calories, the number of calories in the food taken.

The calories under the heading "fat" are computed only from the fat in the cream; the calories under the heading "proteid" are computed from the proteid and sugar in the skimmed milk and cream. In modifications in which cream is used but no skimmed milk, as in the whey mixtures given above, it must be remembered that the calories supplied by the sugar and proteid in the cream are found under the heading " proteid."

This, briefly, is the scope of the card. A knowledge of infant feeding is assumed, and no attempt is made to suggest formulæ which infants at various ages should digest. When a suitable formula is decided upon, the card offers a quick and easy means of determining how that formula may be prepared at home.

Note. - The card is published by F. H. Thomas Company, 691 Boylston Street, Boston, Mass.
OBSERVATIONS ON EUROPEAN AND AMERICAN ORTHOPEDIC APPARATUS.

By william H. KRaUs,

Foreman of the Surgical Appliance Shop at the Massachusetts General Hospital.

(From the Orthopedic Clinic of the Massachusetts General Hospital.)

THE manufacture of apparatus for the correction of deformity has for many years been recognized as a special art. Most of the designs for such apparatus have emanated from the orthopedic specialists, and in European countries this work has engaged the closest attention of the leading members of the profession.

The actual making of these appliances has everywhere been left to the instrument maker, and in this country he is often called upon to be the designer of the apparatus as well. While this practice, except in rare instances, is perhaps to be condemned, yet the average physician in this country lacks either the time or the necessary stimulus to acquaint himself with the details of steel and leather work and often orders apparatus which the trained instrument maker recognizes at once as impractical and not likely to fulfill its purpose.

In order that he might acquire a working knowledge of the principles underlying the manufacture of the more standard forms of apparatus used for many years abroad, and in order that the details of this manufacture might be learned, the writer was assisted by the Massachusetts General Hospital and some of the Boston physicians to visit the principal European instrument shops. It was hoped that thereby much wasteful experimentation might be saved and the proverbially ingenious American mind might start at least from the vantage ground of the knowledge of solutions of many problems which had been worked out in the foreign clinics. Shops in England, France and Germany were visited. The apparatus in these countries differs as much from each other in detail as the products of our shops differ. Each instrument maker was seemingly contented with his work and sure his own type was the most desirable.

The work in Germany proved most interesting and instructive and there, in my opinion, are to be found the most practical and efficient types of apparatus in Europe. Germany has a standard type of her own, originated by Hessing and Hoffa, and so satisfactory does it seem to them that little effort is made to experiment or improve. Owing to the similarity of their types, manufacturers of the principal materials used, such as steel and leather, make a specialty of supplying to this particular trade that which after careful tests has proved most suitable. The steel made especially for apparatus can be obtained in most convenient sizes and of such malleability that it permits working cold to a greater extent than our own common cast steel. The leather used for jackets is especially manufactured and is said to be of secret tannage. It comes in whole hides, which can be cut to better advantage than our ordinary side leather, and is unstretched, permit- 